\title{
Synthesis and Nonlinear Optical Properties of Novel T-type Polyester Containing Thiophene with Enhanced Thermal Stability
}

\author{
Hyo Jin No, You Jin Cho, and Ju-Yeon Lee
}

\author{
Institute of Basic Science, Department of Chemistry, Inje University, Gimhae 621-749, Korea. *E-mail: chemljy@inje.ac.kr \\ Received November 24, 2009, Accepted January 11, 2010
}

\begin{abstract}
A novel T-type polyester 7 containing 1-(2,5-dioxyphenyl)-2-\{5-(1,2,2-tricyanovinyl)-2-thienyl $\}$ ethenes as nonlinear optical (NLO) chromophores, which are part of the polymer backbone, was prepared and characterized. Polyester 7 is soluble in common organic solvents such as dimethylsulfoxide and $N, N$-dimethylformamide. It showed a thermal stability up to $300^{\circ} \mathrm{C}$ in thermogravimetric analysis thermogram and the glass-transition temperature $\left(T_{g}\right)$ obtained from differential scanning calorimetry thermogram was around $113^{\circ} \mathrm{C}$. The second harmonic generation (SHG) coefficient $\left(d_{33}\right)$ of poled polymer films at $1,560 \mathrm{~nm}$ fundamental wavelength was around $1.85 \mathrm{pm} / \mathrm{V}$. The dipole alignment exhibits a greater thermal stability even at $10{ }^{\circ} \mathrm{C}$ higher than $T_{g}$, and there is no SHG decay below $125^{\circ} \mathrm{C}$ due to the partial mainchain character of the polymer structure, which is acceptable for nonlinear optical device applications.
\end{abstract}

Key Words: Nonlinear optics, Polyester, Differential scanning calorimetry, AFM, Second harmonic generation

\section{Introduction}

Recently materials of nonlinear optical (NLO) activity have been extensively studied because of their potential applications in the field of electro-optic devices, including ultrafast optical switches, high-speed optical modulators, and high-density optical data storage media. ${ }^{1-3}$ Among them, NLO polymers are considered candidate materials, mainly because they offer many advantages such as higher nonlinear optical activity, faster response time, high optical damage threshold, low cost, and good processability to form electro-optic devices. One of the current tasks is to design novel NLO polymers having optimized properties. In the developments of NLO polymers for electro-optic device applications, stabilization of electrically induced dipole alignment is one of important criteria; in this context, two approaches to minimize the randomization have been proposed namely the use of cross-linked systems ${ }^{4-7}$ and the utilization of high $T_{g}$ polymers such as polyimides. ${ }^{8}$ Several polyesters with NLO chromophores in the main chain ${ }^{9}$ or in side chain ${ }^{10}$ have been prepared and their properties studied. In general, mainchain NLO polymers have good thermal stability of dipole alignments, but they often do not dissolve in organic solvents, and their intractability make them unusable to fabricate stable films. Side-chain NLO polymer systems have the advantages such as good solubility, homogeneity and high loading level of NLO chromophores relative to the main-chain systems, but they often suffer from poor stability of dipole alignments at high temperatures. Recently we have prepared novel polyesters containing dioxynitrostilbene ${ }^{11-12}$ or dioxybenzylidenemalononitrile $^{13}$ as NLO chromophores. The resulting polymers exhibit enhanced thermal stability of second harmonic generation (SHG), which stems from the stabilization of dipole alignment of the NLO chromophore.

In this work reported here, we have prepared a novel polyester containing 1-(2,5-dioxyphenyl)-2-\{5-(1,2,2,-tricyanovinyl)-2thienyl $\}$ ethene groups as NLO chromophores. We selected the latter because they have a larger hyperpolarizability compared to all benzenoid systems. Furthermore, these 1-(2,5-dioxyethoxyphenyl)-2-\{5-(1,2,2-tricyanovinyl)-2-thienyl $\}$ ethene groups can be incorporated into novel T-type NLO polyesters (see Fig. 1c). The structure of NLO chromophores and these Ttype NLO polyesters have not yet been described in the literature. Thus we formulated a new type of NLO polyester, in which the pendant NLO chromophores are components of the polymer backbone. This mid-type NLO polymer is expected to have the advantages of both main-chain and side-chain NLO polymers namely stable dipole alignment and good solubility. After confirming the structure of the resulting polymer, we investigated its properties: $T_{g}$, thermal stability, surface morphology of polymer films, and second harmonic generation (SHG) activity.

\section{Results and Discussion}

Synthesis and Characterization of Polymer 7. Compound 1 was prepared by the reaction of 2-chloroethyl vinyl ether with 2,5-dihydroxybenzaldehyde. Compound $\mathbf{2}$ was prepared by

(a)

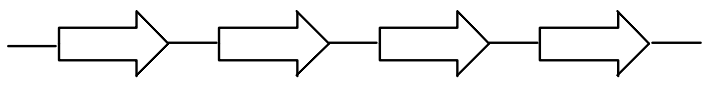

(b)

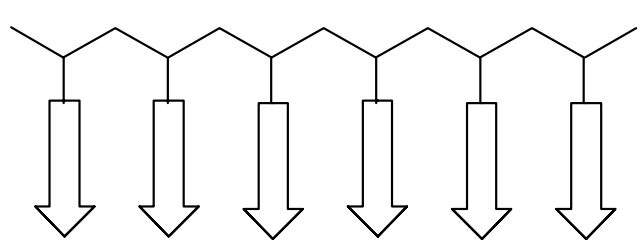

(c)

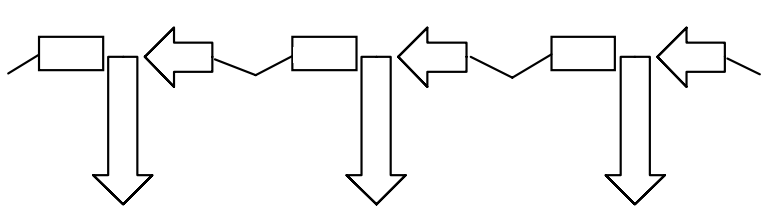

Figure 1. Schematic structures of NLO polymers with chromophores located (a) main-chain, (b) side-chain, and (c) main/side chain (T-type). 
the bromination of 2-methylthiophene with $N$-bromosuccinimide. Compound $\mathbf{3}$ was prepared by Arbuzov reaction from compound $\mathbf{2}$ and triethyl phosphite. Compound $\mathbf{4}$ was prepared by Horner-Emmons olefination with compounds 1 and 3. Compound 5 was prepared by acid-catalyzed hydrolysis of 4 in DMF. Polyester 6 was prepared by the polycondensation reaction between a diol 5 and terephthaloyl chloride in a dry DMF solvent. The polymerization yield was $88-90 \%$. Polymer 6 was reacted with tetracyanoethylene in anhydrous $\mathrm{DMF}^{14}$ to yield polyester 7 containing 1-(2,5-dioxyphenyl)-2-\{5-(1,2,2-tricyanovinyl)-2thienyl $\}$ ethene groups as NLO chromophores. The synthetic route for polymer 7 is presented in Scheme 1. The resulting polymer was purified by Soxhlet extraction for 2 days with methanol as a solvent.

The chemical structure of the polymer was identified using ${ }^{1} \mathrm{H}$ NMR, IR spectra, and elemental analysis. Elemental analysis results fit the polymer structures. ${ }^{1} \mathrm{H}$ NMR spectrum of the polymer 7 showed a signal broadening due to polymerization, but the chemical shifts were consistent with the proposed polymer structure. The IR spectrum of polymer 7 showed strong carbonyl peaks near $1720 \mathrm{~cm}^{-1}$ indicating the presence of ester bond. The spectrum also shows strong absorption peak near $2219 \mathrm{~cm}^{-1}$ indicating the presence of nitrile group. These results are consistent with the proposed structures, indicating that the tricyanovinyl groups are introduced well to the thiophene rings. The molecular weights were determined using GPC with polystyrene as the standard and THF as the eluent. The number average molecular weight $\left(M_{\mathrm{n}}\right)$ of the polymer 7 , determined by GPC, is $17200\left(M_{\mathrm{w}} / M_{\mathrm{n}}=1.94\right)$. The polymer 7 is soluble in common solvents such as acetone, DMF, and DMSO, but is not soluble in methanol and diethyl ether. The inherent viscosity values is in the range $0.28-0.30 \mathrm{dL} / \mathrm{g}$. Polymer 7 is a violet colored amorphous material. Polymer film cast from DMF solution is somewhat brittle probably because of the polar pendant groups and/ or rather low molecular weight. Polymer 7 shows strong absorption near $527 \mathrm{~nm}$ due to the NLO chromophore 1-(2,5-dioxyphenyl)-2-\{5-(1,2,2-tricyanovinyl)-2-thienyl) $\}$ ethene group.

The structural feature of this polymerization system is that it gives unprecedented T-type NLO polymers, in which the pendant NLO chromophores are part of the polymer backbone. This mid-type NLO polymer is expected to have the advantages of both main-chain and side-chain NLO polymers. Thus, we obtained a new type of NLO polyester with side-chain and mainchain characteristics. Having well defined T-type polyester 7, we investigated its properties.

Thermal Properties of the Polymer. The thermal behavior of the polymer was investigated using thermogravimetric analysis (TGA) and differential scanning calorimeter (DSC) to determine the thermal degradation pattern and glass transition temperature. The results are summarized in Table 1 . The TGA and DSC thermograms of the polymer 7 are shown in Fig. 2 and Fig. 3, respectively. Polymer 7 has a thermal stability up to $300{ }^{\circ} \mathrm{C}$ according to its TGA thermogram. The $T_{g}$ value of the polymer 7 measured by DSC is near $113^{\circ} \mathrm{C}$. This $T_{g}$ value is lower than that of the Y-type polyester, which is near $134^{\circ} \mathrm{C}$. ${ }^{15}$ The TGA and DSC studies show that the decomposition temperature of the polymer 7 is higher than the corresponding $T_{g}$ value. This indicates that high-temperature poling for a short term is feasible without

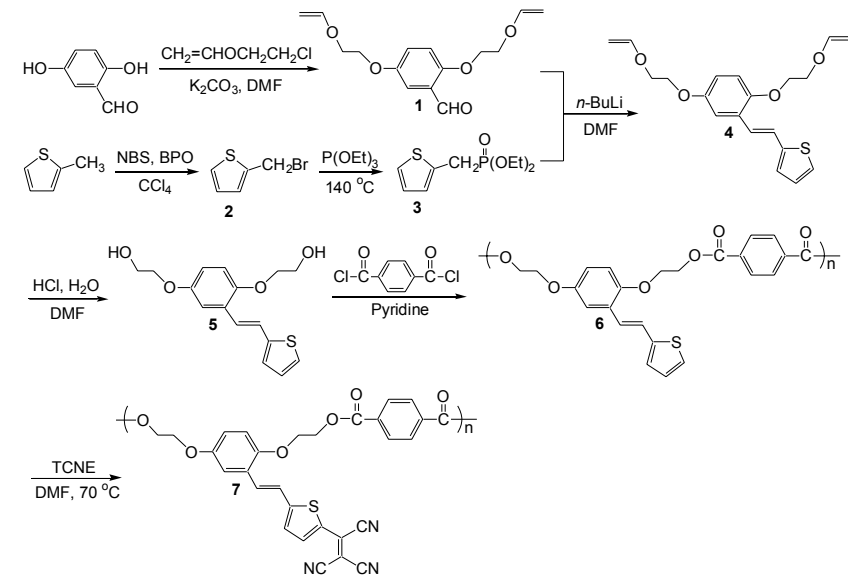

Scheme 1. Synthetic scheme and structure of polymer 7

Table 1. Thermal Properties of Polymer 7

\begin{tabular}{cccccc}
\hline & & \multicolumn{3}{c}{ Degradation temp $\left({ }^{\circ} \mathrm{C}\right)^{b}$} & Residue at \\
\cline { 3 - 6 } Polymer & $T_{\mathrm{g}}{ }^{a}\left({ }^{\circ} \mathrm{C}\right)$ & $\begin{array}{c}5 \mathrm{wt} \% \\
- \text { loss }\end{array}$ & $\begin{array}{c}20 \mathrm{wt} \% \\
- \text { loss }\end{array}$ & $\begin{array}{c}40 \mathrm{wt} \% \\
- \text { loss }\end{array}$ & $\begin{array}{c}800{ }^{\circ} \mathrm{C} \\
(\%)^{b}\end{array}$ \\
\hline 7 & 113 & 312 & 380 & 513 & 45.3 \\
\hline
\end{tabular}

${ }^{a}$ Determined from DSC curves measured with a TA 2920 differential scanning calorimeter with a heating rate of $10^{\circ} \mathrm{C} / \mathrm{min}$ under nitrogen atmosphere. ${ }^{b}$ Determined from TGA curves measured with a TA Q50 thermogravimetric analyzer with a heating rate of $10{ }^{\circ} \mathrm{C} / \mathrm{min}$ under nitrogen atmosphere.

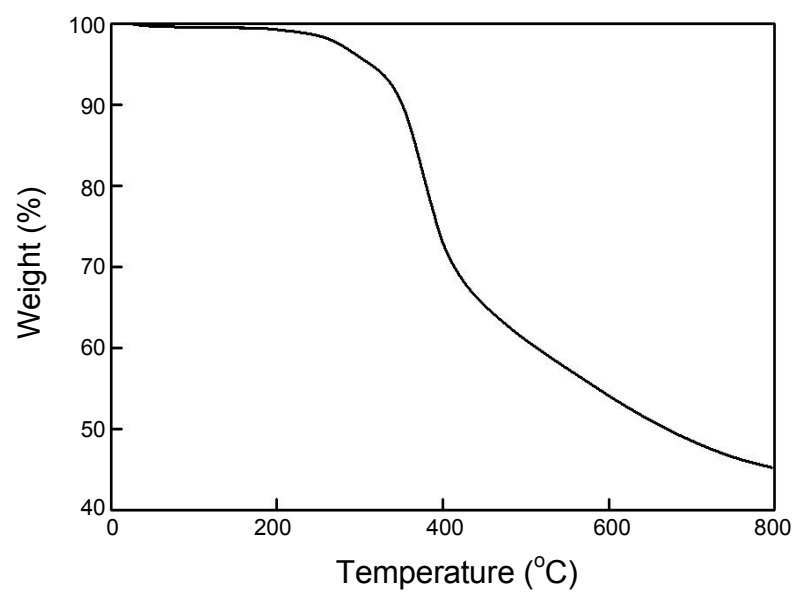

Figure 2. TGA thermogram of polymer 7 obtained at a heating rate of $10^{\circ} \mathrm{C} /$ min under nitrogen.

\section{damaging the NLO chromophore.}

Nonlinear Optical Properties of the Polymer. The NLO properties of polymer were studied using the SHG method. To induce noncentrosymmetric polar order, the spin-coated polymer films were corona-poled. As the temperature was raised gradually to $120^{\circ} \mathrm{C}, 6.5 \mathrm{kV}$ of corona voltage was applied and this temperature was maintained for $30 \mathrm{~min}$. The poling was confirmed from UV-visible spectra. Fig. 4 shows the UV-visible absorption spectra of the polymer 7 before and after poling. After electric poling, the dipole moments of the NLO chro- 


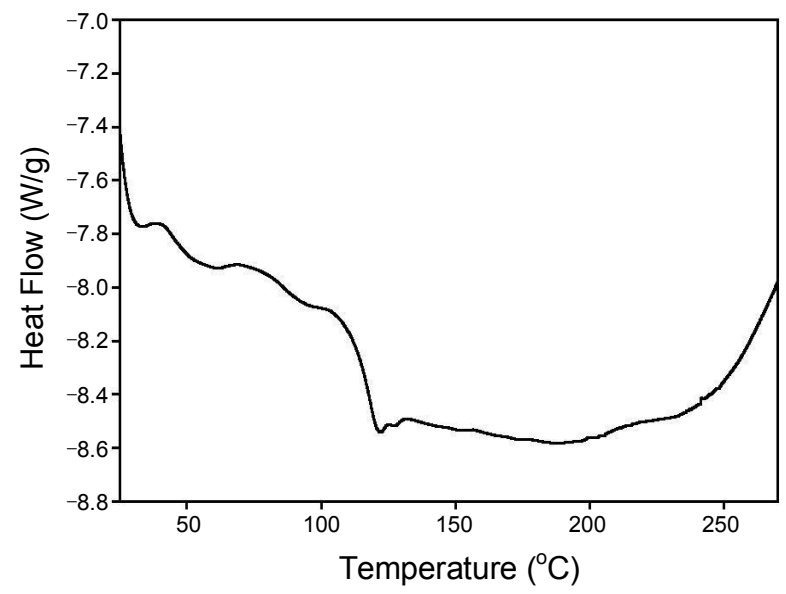

Figure 3. DSC thermogram of polymer 7 obtained at a heating rate of $10{ }^{\circ} \mathrm{C} / \mathrm{min}$ under nitrogen.

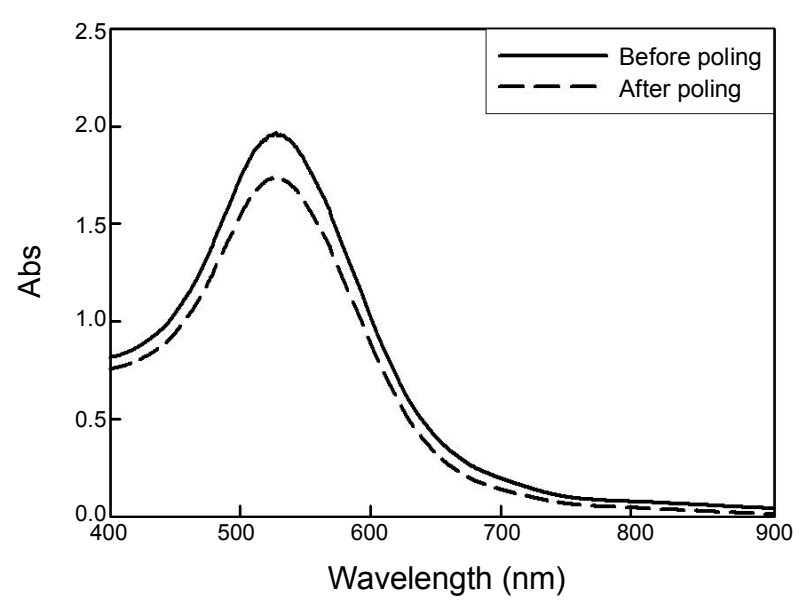

Figure 4. UV-visible absorption spectra of a film of polymer 7 before and after poling.

mophores were aligned and UV-visible absorption of polymer 7 exhibits a decrease in absorption due to birefringence. From the absorbance change, the order parameter of the poled film could be estimated, which is related to the poling efficiency. The estimated order parameter value $\Phi$ was equal to 0.12 for polymer $7\left(\Phi=1-\mathrm{A}_{1} / \mathrm{A}_{0}\right.$, where $\mathrm{A}_{0}=1.9642$ and $\mathrm{A}_{1}=1.7354$ are the absorbances of the polymer film before and after poling, respectively).

For the purpose of investigating surface morphology of polymer films, domain structures of NLO chromophores for the thin-film samples were obtained using atomic force microscopy (AFM). Fig. 5 shows AFM scans of a spin-coated film of polymer 7 before and after poling. AFM images show that the surface of the film sample is extremely flat and clean before poling (see Fig. 5a). However, this good quality film was dramatically changed after poling, resulting in numerous hills and valleys in the surface structure, which means that the NLO-chromophores are aligned in the poling direction as shown in Fig. $5 b$.

The refractive index of the sample was measured using the optical transmission technique. ${ }^{16}$ The transmittance of thin film gives information on the thickness, refractive index and extinc-
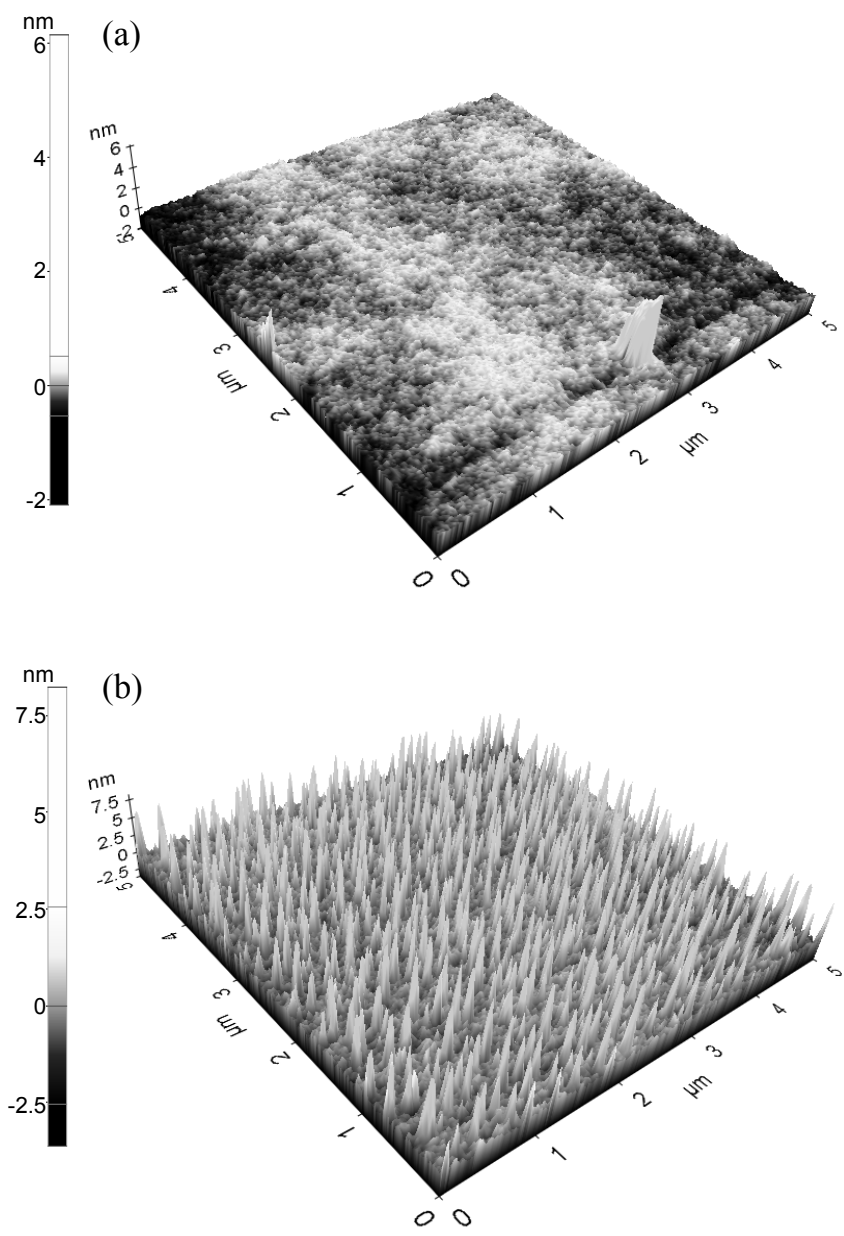

Figure 5. AFM images of spin-coated film of polymer 7: (a) before corona-poling; (b) after corona-poling.

tion coefficient. Thus, we could determine those parameters by analyzing the transmittance. SHG measurements were performed at a fundamental wavelength of $1,560 \mathrm{~nm}$ using a mode locked Nd-YAG laser and optical parametric oscillator (OPO). In order to determine the microscopic second-order susceptibility of the polymers, the angular SHG dependence was recorded. The SHG values were compared with those obtained from a Y-cut quartz plate. To calculate the $d_{31}$ and $d_{33}$ values, both $s$-polarized and $p$-polarized IR laser were directed at the samples. Nonlinear optical properties of polymer 7 are summarized in Table 2. SHG coefficients $\left(d_{33}\right)$ were derived from the analysis of measured Maker-fringes with the Pascal fitting program according to the literature procedure. ${ }^{17}$ The values of $d_{31}$ and $d_{33}$ for polymer 7 are $0.63 \mathrm{pm} / \mathrm{V}$ and $1.85 \mathrm{pm} / \mathrm{V}$, respectively. This value is lower than that of the Y-type polyester, which is near $2.82 \mathrm{pm} / \mathrm{V} .{ }^{15}$ Since the second harmonic wavelength is at $780 \mathrm{~nm}$, which is not in the absorptive region of the resulting polyester, there is no resonant contribution to this $d_{33}$ value. In the isotropic model, the ratio of $d_{33} / d_{31}$ is predicted to be about 3 . Our $d_{33} / d_{31}$ value of 2.94 is in good agreement with the predicted value.

To evaluate the high-temperature stability of the polymer, 


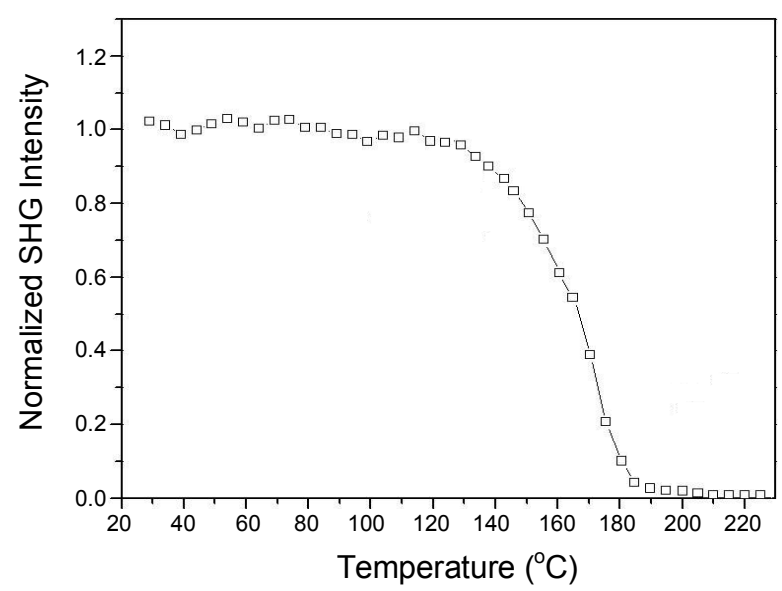

Figure 6. Normalized SHG signal of polymer 7 as a function of temperature at a heating rate of $4{ }^{\circ} \mathrm{C} / \mathrm{min}$.

Table 2. Nonlinear Optical Properties of Polymer 7

\begin{tabular}{ccccccc}
\hline Polymer & $\begin{array}{c}\lambda_{\max }{ }^{a} \\
(\mathrm{~nm})\end{array}$ & $\begin{array}{c}d_{33}{ }^{b} \\
(\mathrm{pm} / \mathrm{V})\end{array}$ & $\Phi^{c}$ & $\begin{array}{c}\text { film } \\
\text { thickness }^{d} \\
(\mu \mathrm{m})\end{array}$ & $\begin{array}{c}d_{31}{ }^{b} \\
(\mathrm{pm} / \mathrm{V})\end{array}$ & $n$ \\
\hline 7 & 527 & 1.85 & 0.12 & 0.51 & 0.63 & 1.512 \\
\hline
\end{tabular}

${ }^{a}$ Polymer film after corona poling. ${ }^{b} \mathrm{SHG}$ coefficients $\left(d_{33}\right)$ were derived from the analysis of measured Maker-fringes. ${ }^{17} \mathrm{SHG}$ measurements were performed at a fundamental wavelength of $1064 \mathrm{~nm}$ using a mode locked Nd-YAG laser. ${ }^{c}$ Order parameter $\Phi=1-\mathrm{A}_{1} / \mathrm{A}_{0}$, where $\mathrm{A}_{0}$ and $\mathrm{A}_{1}$ are the absorbances of the polymer film before and after corona poling, respectively. ${ }^{d}$ Film thickness was determined using the optical transmission technique. ${ }^{16}$

we studied the temporal stability of the SHG signal. Fig. 6 shows the dynamic thermal stability study of the NLO activity of a film of polymer 7. To investigate the real time NLO decay of the SHG signal of the poled polymer film as a function of temperature, in situ SHG measurements were performed at a heating rate of $4{ }^{\circ} \mathrm{C} / \mathrm{min}$ from 30 to $220^{\circ} \mathrm{C}$. The polymer film exhibited a thermal stability even at $10^{\circ} \mathrm{C}$ higher than $T_{g}$ and no significant SHG decay was observed below $125^{\circ} \mathrm{C}$. This SHG thermal stability is at the high rank in the known NLO polyesters. In general, side-chain NLO polymers lose the thermal stability of dipole alignment below $T_{g}$. Stabilization of dipole alignment is a characteristic of main-chain NLO polymers. The enhanced thermal stability of second harmonic generation of polymer 7 is due to the stabilization of dipole alignment of NLO chromophore, which stems from the partial main-chain character of the polymer structure. Thus, we obtained a new type of NLO polyester having the advantages of both main-chain and side-chain NLO polymers namely stable of dipole alignment and good solubility.

\section{Conclusions}

We synthesized novel T-type polyester 7 with pendant NLO chromophores, which are part of the polymer main chain. This mid-type NLO polyurethane is soluble in common organic solvents. The resulting polymer 7 shows a thermal stability up to $300{ }^{\circ} \mathrm{C}$ from TGA thermograms with $T_{g}$ value near $113{ }^{\circ} \mathrm{C}$. The SHG coefficient $\left(d_{33}\right)$ of corona-poled polymer film was
$1.85 \mathrm{pm} / \mathrm{V}$. The structural feature of this polymer is that it exhibits a greater thermal stability even at $10^{\circ} \mathrm{C}$ higher than $T_{g}$ and no significant SHG decay is observed below $125^{\circ} \mathrm{C}$. This SHG thermal stability is similar with those of Y-type polyesters containing the same NLO chromophores, which are in the range $125-135^{\circ} \mathrm{C} .{ }^{15,18}$ This high thermal stability of optical nonlinearity stems from the stabilization of dipole alignment of the NLO chromophores, which constitute a part of the polymer backbone. We are now in the process of extending the polymerization system to the synthesis of other type of NLO polymers and the results will be reported elsewhere.

\section{Experimental Section}

Materials. Reagent grade chemicals were purchased from Aldrich and purified by either distillation or recrystallization before use. 2-Methylthiophene, triethyl phosphite, $n$-butyllithium, 2,5-dihydroxybenzaldehyde, $\mathrm{N}$-bromosuccinimide, and 2-chloroethyl vinyl ether were used as received. Tetracyanoethylene (TCNE) and terephthaloyl chloride (TPC) were purified by sublimation under vacuum. $N, N$-Dimethylformamide (DMF) was purified by drying with anhydrous calcium sulfate, followed by distillation under reduced pressure.

Measurements. Infrared (IR) spectra were taken on a Shimadzu FT IR-8201PC infrared spectrophotometer. ${ }^{1} \mathrm{H}$ NMR spectra were obtained on a Varian 300MHz NMR spectrometer. UV-visible absorption spectra were measured on a Shimadzu UV-3100S spectrophotometer. Elemental analyses were performed using a Perkin-Elmer $2400 \mathrm{CHN}$ elemental analyzer. $T_{\mathrm{g}}$ values were measured using a TA 2920 differential scanning calorimeter DSC in a nitrogen atmosphere. TA Q50 thermogravimetric analyzer with a heating rate of $10{ }^{\circ} \mathrm{C} \mathrm{min}{ }^{-1}$ up to $800^{\circ} \mathrm{C}$ was used for the thermal degradation of polymers under nitrogen. The number-average molecular weight $\left(M_{\mathrm{n}}\right)$ and weight-average molecular weight $\left(M_{\mathrm{w}}\right)$ of the polymers were estimated using gel permeation chromatography (GPC; styragel HR5E4E columns; tetrahydrofuran (THF) solvent). AFM images were recorded with a Park Science Instrument Autoprobe $\mathrm{CP}$, operated in a contact mode, which measures topography. Viscosity values were obtained using a Cannon-Fenske viscometer.

Film Preparation and SHG Measurement. SHG measurements were performed according to a literature procedure. ${ }^{15}$ The polymer film was prepared from a $10 \mathrm{wt} \%$ polymer solution in DMF deposited on an indium-tin oxide (ITO) covered glass. The refractive index of the sample was measured using the optical transmission technique. ${ }^{16}$ Second harmonic generation (SHG) measurement was carried out one day after poling. The transmittance of thin film gives information on the thickness, refractive index and extinction coefficient. Thus, we could determine those parameters by analyzing the transmittance. SHG measurements were performed at a fundamental wavelength of $1,560 \mathrm{~nm}$ using a mode locked Nd-YAG laser and optical parametric oscillator (OPO). The Maker Fringe pattern was obtained from measuring the SHG signal at $0.5^{\circ}$ intervals using a rotation stage. SHG coefficients $\left(d_{33}\right)$ were derived from the analysis of measured Maker-fringes. ${ }^{17}$

Preparation of 2,5-Di-(2'-vinyloxyethoxy)benzaldehyde (1). 
2,5-Dihydroxybenzaldehyde ( $13.8 \mathrm{~g}, 0.10 \mathrm{~mol})$, anhydrous potassium carbonate $(82.9 \mathrm{~g}, 0.60 \mathrm{~mol})$, and 2-chloroethyl vinyl ether $(26.6 \mathrm{~g}, 0.25 \mathrm{~mol})$ were dissolved in $400 \mathrm{~mL}$ of dry DMF under nitrogen. The mixture was refluxed in an oil bath kept at $80^{\circ} \mathrm{C}$ for $15 \mathrm{~h}$ under nitrogen. The resulting solution was cooled to room temperature, diluted with $300 \mathrm{~mL}$ of water, and extracted with $300 \mathrm{~mL}$ of diethyl ether three times. The organic layer was washed with saturated aqueous sodium chloride solution, and dried with anhydrous magnesium sulfate. Rotary evaporation of diethyl ether gave crude product, which was recrystallized from 1-butanol yielded $24.5 \mathrm{~g}$ ( $88 \%$ yield) of pure product 1 . ${ }^{1} \mathrm{HNMR}\left(\mathrm{CDCl}_{3}\right) \delta 3.98-4.34\left(\mathrm{~m}, 12 \mathrm{H}, 2 \mathrm{CH}_{2}=, 2-\mathrm{O}-\mathrm{CH}_{2}-\mathrm{CH}_{2}-\right.$ O-), 6.45-6.58 (m, 2H, 2 =CH-O-), 6.92-6.99 (m, 1H, aromatic), 7.15-7.21 (m, 1H, aromatic), 7.33-7.36 (d, 1H, aromatic), 10.46 (s, 1H, -CHO). IR (KBr) 3096, 3075 (w, =C-H), 2941, 2882 (s, $\mathrm{C}-\mathrm{H}), 1676(\mathrm{vs}, \mathrm{C}=\mathrm{O}), 1624(\mathrm{vs}, \mathrm{C}=\mathrm{C}) \mathrm{cm}^{-1}$.

Preparation of 2-Bromomethylthiophene (2). Compound 2 was prepared according to a literature procedure. ${ }^{14}$ 2-Methylthiophene $(9.82 \mathrm{~g}, 0.10 \mathrm{~mol}), N$-bromosuccinimide $(17.80 \mathrm{~g}$, $0.10 \mathrm{~mol})$, and benzoylperoxide $(0.24 \mathrm{~g}, 1.0 \mathrm{mmol})$ were dissolved in $80 \mathrm{~mL}$ of anhydrous carbon tetrachloride under a nitrogen atmosphere. The mixture was refluxed with vigorous stirring at $80{ }^{\circ} \mathrm{C}$ for $3 \mathrm{~h}$ under nitrogen and then cooled to room temperature. The succinimide produced was filtered out with suction and water $(60 \mathrm{~mL})$ was added to the filtrate, which was extracted with diethyl ether $(60 \mathrm{~mL})$ three times. The organic layer was washed successively with saturated aqueous sodium bicarbonate $(60 \mathrm{~mL})$ and sodium chloride solution $(60 \mathrm{~mL})$, which was dried with anhydrous potassium carbonate. After evaporation of solvent by rotary evaporator, the crude product was purified by distillation under reduced pressure to yield $11.95 \mathrm{~g}$ (75\% yield) of $2 . \mathrm{Bp}=45-46{ }^{\circ} \mathrm{C} / 5 \mathrm{mmHg}$. ${ }^{1} \mathrm{H}$ NMR $\left(\mathrm{CDCl}_{3}\right) \delta 4.75\left(\mathrm{~s}, 2 \mathrm{H},-\mathrm{CH}_{2} \mathrm{Br}\right), 6.92(\mathrm{~m}, 1 \mathrm{H}$, aromatic), 7.09 (m, 1H, aromatic), $7.31(\mathrm{~m}, 1 \mathrm{H}$, aromatic). $\mathrm{IR}$ ( $\mathrm{KBr}$ disc) 1673 (m, C=C), 1211 (s, C-S), 701 (vs, C-Br) $\mathrm{cm}^{-1}$.

Preparation of Diethyl 2-thienylmethylphosphonate (3). 2-Bromomethylthiophene $(5.97 \mathrm{~g}, 25 \mathrm{mmol})$ was added to triethyl phosphite (4.49 g, $27 \mathrm{mmol})$. The resulting mixture was heated at $80^{\circ} \mathrm{C}$ for $12 \mathrm{~h}$ and then cooled to room temperature and then ethyl bromide produced was distilled off and water $(60 \mathrm{~mL})$ was added to the filtrate, which was extracted with diethyl ether $(60 \mathrm{~mL})$ three times. The organic layer was washed with sodium chloride solution $(60 \mathrm{~mL})$, which was dried with anhydrous potassium carbonate. After evaporation of solvent by rotary evaporator, the obtained crude product was purified by distillation under reduced pressure to yield $5.39 \mathrm{~g} \mathrm{(92 \%} \mathrm{yield)}$ of 3. $\mathrm{Bp}=95-96{ }^{\circ} \mathrm{C} / 2 \mathrm{mmHg} .{ }^{1} \mathrm{H} \mathrm{NMR}\left(\mathrm{CDCl}_{3}\right) \delta 1.22(\mathrm{t}, 6 \mathrm{H}$, $\left.2-\mathrm{CH}_{3}\right), 3.31$ (d, 2H, -Ar- $\left.\mathrm{CH}_{2}-\mathrm{PO}-\right), 4.03$ (m, 4H, $2-\mathrm{O}-\mathrm{CH}_{2}-$ ), $6.91(\mathrm{~m}, 2 \mathrm{H}$, aromatic), $7.15(\mathrm{~m}, 1 \mathrm{H}$, aromatic). IR (KBr disc) $3123(\mathrm{w},=\mathrm{CH}), 2982(\mathrm{~m}, \mathrm{C}-\mathrm{H}), 1674(\mathrm{w}, \mathrm{C}=\mathrm{C}), 1247(\mathrm{~s}, \mathrm{P}=\mathrm{O})$ $\mathrm{cm}^{-1}$. Anal. Calcd for $\mathrm{C}_{9} \mathrm{H}_{15} \mathrm{O}_{3} \mathrm{PS}: \mathrm{C}, 46.15 ; \mathrm{H}, 6.45 ; \mathrm{S}, 13.69$. Found: C, 46.23; H, 6.49; S, 13.65.

Preparation of 1-\{2,5-Di-(2-vinyloxyethoxy)phenyl $\}$-2-(2thienyl)ethene (4). Under nitrogen at $0{ }^{\circ} \mathrm{C}, n$-butyllithium $(18.75$ $\mathrm{mL}, 30 \mathrm{mmol}, 1.6 \mathrm{~mol} \mathrm{~L}^{-1}$ in hexane) was added to the solution of compound 3 (5.86 g, $25 \mathrm{mmol}$ ) in $10 \mathrm{~mL}$ of anhydrous DMF and stirred for $30 \mathrm{~min}$. To this reaction mixture was added compound 1 (5.56 g, $20 \mathrm{mmol})$ in $10 \mathrm{~mL}$ of anhydrous DMF slowly at $0{ }^{\circ} \mathrm{C}$ under nitrogen. The solution was stirred for $12 \mathrm{~h}$ at $0{ }^{\circ} \mathrm{C}$ under nitrogen. Water $(60 \mathrm{~mL})$ was added to the filtrate, which was extracted with diethyl ether $(60 \mathrm{~mL})$ three times. The organic layer was washed successively with saturated aqueous sodium bicarbonate $(60 \mathrm{~mL})$ and sodium chloride solution (60 $\mathrm{mL}$ ), which was dried with anhydrous potassium carbonate. Evaporation of solvent by rotary evaporator gave crude product, which was purified by column chromatography (ethyl acetate / $n$-hexane $=1 / 4, \mathrm{vol} / \mathrm{vol})$ to yield $5.24 \mathrm{~g}(74 \%$ yield $)$ of $4 .{ }^{1} \mathrm{H}$ NMR (DMSO- $\left.d_{6}\right) \delta 3.96-4.08\left(\mathrm{~m}, 6 \mathrm{H}, \mathrm{CH}_{2}=\right.$, $\left.-\mathrm{O}-\mathrm{CH}_{2}-\mathrm{CH}_{2}-\mathrm{O}-\right)$, 4.17-4.33 (m, 6H, $\mathrm{CH}_{2}=$, $\left.-\mathrm{O}-\mathrm{CH}_{2}-\mathrm{CH}_{2}-\mathrm{O}-\right)$, 6.54-6.66 (m, 2H, 2 $=\mathrm{CH}-\mathrm{O}-), 6.81-6.87(\mathrm{q}, 1 \mathrm{H},-\mathrm{CH}=), 6.97-7.01(\mathrm{~d}, 1 \mathrm{H},-\mathrm{CH}=)$, 7.05-7.16 (m, 3H, aromatic), 7.23-7.27 (d, 1H, aromatic), 7.44$7.48(\mathrm{~d}, 1 \mathrm{H}$, aromatic), 7.51-7.57 (d, 1H, aromatic). IR (KBr disc) $3108(\mathrm{w},=\mathrm{C}-\mathrm{H}), 2928,2873(\mathrm{~m}, \mathrm{C}-\mathrm{H}), 1618(\mathrm{vs}, \mathrm{C}=\mathrm{C})$ $\mathrm{cm}^{-1}$. Anal. Calcd for $\mathrm{C}_{20} \mathrm{H}_{22} \mathrm{O}_{4} \mathrm{~S}: \mathrm{C}, 67.01 ; \mathrm{H}, 6.19 ; \mathrm{S}, 8.95$. Found: C, 67.08; H, 6.25; S, 8.89.

Preparation of 1-\{2,5-Di-(2-hydroxyethoxy)phenyl\}-2-(2thienyl)ethene (5). Aqueous hydrochloric acid (1.5 mol L ${ }^{-1}$, $12 \mathrm{~mL}$ ) was slowly added to a solution of compound 4 (3.58 g, $10 \mathrm{mmol}$ ) in $30 \mathrm{~mL}$ of dry DMF with stirring under nitrogen at $0{ }^{\circ} \mathrm{C}$. The mixture was stirred at $0^{\circ} \mathrm{C}$ for $5 \mathrm{~h}$ under nitrogen. The resulting solution was poured into $100 \mathrm{~mL}$ of ice water and stirred. The product obtained was separated by suction and washed with $30 \%$ aqueous ethanol. Thus obtained product was recrystallized from ethanol to give $2.69 \mathrm{~g}$ (yield $88 \%$ ) of 5 . ${ }^{1} \mathrm{H}$ NMR $\left(\mathrm{DMSO}-d_{6}\right) \delta 3.67-3.79$ (m, 4H, -O-CH $2-\mathrm{CH}_{2}-\mathrm{O}-$ ), 3.95-4.01 (t, $\left.4 \mathrm{H},-\mathrm{O}-\mathrm{CH}_{2}-\mathrm{CH}_{2}-\mathrm{O}-\right), 4.87$ (t, 1H, -O-H), 4.94 (t, $\left.1 \mathrm{H},-\mathrm{O}-\mathrm{H}\right)$, 6.78-6.84 (q, $1 \mathrm{H},-\mathrm{CH}=), 6.94-6.97(\mathrm{~d}, 1 \mathrm{H},-\mathrm{CH}=)$, 7.04-7.09 (m, $1 \mathrm{H}$, aromatic), 7.15-7.24 (m, 3H, aromatic), 7.44-7.55 (q, 2H, aromatic). IR (KBr disc) 3266 (s, O-H), 2932, 2864 (m, C-H), $1602(\mathrm{~m}, \mathrm{C}=\mathrm{C}) \mathrm{cm}^{-1}$. Anal. Calcd for $\mathrm{C}_{16} \mathrm{H}_{18} \mathrm{O}_{4} \mathrm{~S}: \mathrm{C}, 62.72 ; \mathrm{H}$, 5.92; S, 10.47. Found: C, 62.80; H, 5.96; S, 10.53.

Synthesis of Polyester 6. Terephthaloyl chloride (2.03 g, 10 $\mathrm{mmol}$ ) and diol 5 (3.06 g, $10 \mathrm{mmol})$ were dissolved in $25 \mathrm{~mL}$ of anhydrous pyridine under nitrogen. The resulting solution was refluxed in an oil bath kept at $80^{\circ} \mathrm{C}$ under a nitrogen atmosphere. After heating $24 \mathrm{~h}$ with stirring the resulting polymerization solution was poured into $400 \mathrm{~mL}$ of methanol. The precipitated polymer was collected and re-precipitated from DMSO into methanol. The polymer was further purified by extraction in a Soxhlet extractor with methanol and dried under vacuum, yielding $3.92 \mathrm{~g}(90 \%$ yield $)$ of polymer 6 . Inherent viscosity $\left(\eta_{\text {inh }}\right)=$ $0.30 \mathrm{dL} \mathrm{g}^{-1}\left(\mathrm{c}=0.5 \mathrm{~g} \mathrm{dL}^{-1}\right.$ in DMSO at $\left.25^{\circ} \mathrm{C}\right) .{ }^{1} \mathrm{H}$ NMR (DMSO$\left.d_{6}\right) \delta$ 4.27-4.38 (s, 4H, 2 - $\mathrm{CH}_{2}-\mathrm{O}-$ ), 4.57-4.72 (d, 4H, 2 Ph-O$\mathrm{CH}_{2}-$ ), 6.82-6.95 (m, 2H, - $\mathrm{CH}=\mathrm{CH}-$ ), 6.95-7.12 (m, 3H, aromatic), 7.22-7.31 (s, 1H, aromatic), 7.34-7.56 (m, 2H, aromatic), 7.91-8.11 (m, 4H, aromatic). IR (KBr disc) 3067 (w, =C-H), $2951(\mathrm{~m}, \mathrm{C}-\mathrm{H}), 1720$ (vs, C=O), $1630(\mathrm{~s}, \mathrm{C}=\mathrm{C}) \mathrm{cm}^{-1}$. Anal. Calcd for $\left(\mathrm{C}_{24} \mathrm{H}_{20} \mathrm{O}_{6} \mathrm{~S}\right)_{\mathrm{n}}: \mathrm{C}, 66.04 ; \mathrm{H}, 4.62 ; \mathrm{S}, 7.35$. Found: $\mathrm{C}, 66.13 ; \mathrm{H}$, 4.69; S, 7.27.

Synthesis of Polymer 7. Tetracyanoethylene (1.28 g, 10 $\mathrm{mmol}$ ) was added slowly to a solution of polymer $6(3.71 \mathrm{~g}$, $8.5 \mathrm{mmol}$ ) dissolved in $30 \mathrm{~mL}$ of DMF with stirring at room temperature under nitrogen. The resulting solution was heated in an oil bath kept at $70{ }^{\circ} \mathrm{C}$ for $12 \mathrm{~h}$ under a nitrogen atmosphere. The resulting polymerization solution was cooled to room temperature and poured into $400 \mathrm{~mL}$ of methanol. The preci- 
pitated polymer was collected and re-precipitated from DMSO into methanol. The polymer was further purified by extraction in a Soxhlet extractor with methanol and dried under vacuum, yielding $4.09 \mathrm{~g}$ ( $88 \%$ yield) of polymer 7 . Inherent viscosity $\left(\eta_{\text {inh }}\right)=0.28 \mathrm{dL} \mathrm{g}^{-1}\left(\mathrm{c}=0.5 \mathrm{~g} \mathrm{dL}^{-1}\right.$ in DMSO at $\left.25^{\circ} \mathrm{C}\right) .{ }^{1} \mathrm{H} \mathrm{NMR}$ $\left(\mathrm{DMSO}-d_{6}\right) \delta$ 4.26-4.45 (s, 4H, $2-\mathrm{CH}_{2}-\mathrm{O}-$ ) , 4.54-4.78 (d, 4H, $\left.2 \mathrm{Ph}-\mathrm{O}-\mathrm{CH}_{2}-\right), 6.84-7.72(\mathrm{~m}, 6 \mathrm{H},-\mathrm{CH}=\mathrm{CH}-$, aromatic), 7.85$8.23(\mathrm{~m}, 5 \mathrm{H}$, aromatic). IR (KBr disc) $3085(\mathrm{w},=\mathrm{C}-\mathrm{H}), 2954(\mathrm{~m}$, C-H), 2219 (s, CN), 1720 (vs, C=O), 1627 (s, C=C) $\mathrm{cm}^{-1}$. Anal. Calcd for $\left(\mathrm{C}_{29} \mathrm{H}_{19} \mathrm{~N}_{3} \mathrm{O}_{6} \mathrm{~S}\right)_{\mathrm{n}}$ : C, 64.80; H, 3.55; N, 7.81.; S, 5.97. Found: C, 64.92; H, 3.63; N, 7.74; S, 5.91.

Acknowledgments. This work was supported by the 2009 Inje University research grant.

\section{References}

1. Lee, C.; Park, S.-K.; Yang, M.; Lee, N.-S.; Kim, N. J. Bull. Korean Chem. Soc. 2007, 28, 447.

2. Yoon, Z. S.; Easwaramoorthi, S.; Kim, D. Bull. Korean Chem. Soc. 2008, 29, 197.

3. Jin, F.-L.; Park, S.-J. Bull. Korean Chem. Soc. 2008, 29, 2521.

4. Han, K. S.; Park, S. K.; Shim, S. Y.; Jahng, W. S.; Kim, N. J. Bull.
Korean Chem. Soc. 1998, 19, 1165.

5. Han, K. S.; Park, S. K,; Shim, S. Y.; Lee, Y. S.; Jahng, W. S.; Kim, N. J. Bull. Korean Chem. Soc. 1998, 19, 1168.

6. Cho, B. R.; Kim, Y. H.; Son, K. W.; Khalil, C.; Kim, Y. H.; Jeon, S.-J. Bull. Korean Chem. Soc. 2002, 23, 1253.

7. Moon, J. R.; Kim, B. S.; Kim, J.-H. Bull. Korean Chem. Soc. 2006, 27, 981.

8. Ryu, S.; Kim, J. H.; Lee, S. H.; Lee, M.-H. Bull. Korean Chem. Soc. 2008, 29, 1689.

9. Lee, J.-H.; Lee, K.-S. Bull. Korean Chem. Soc. 2000, $21,847$.

10. Lee, S.-H.; Kim, Y.-K.; Won, Y.-H. Macromolecules 1999, 32, 342.

11. Lee, J.-Y.; Jung, W.-T.; Lee, W.-J. Polym. Int. 2006, 55, 248.

12. Lee, J.-Y.; Kim, J.-H.; Jung, W.-T. Bull. Korean Chem. Soc. 2007, 28,329 .

13. Lee, J.-Y.; Kim, J.-H.; Won, D.-S.; Jang, H.-N. Bull. Korean Chem. Soc. 2007, 28, 1433.

14. Woo, H. Y.; Shim, H. K.; Lee, K. S. Polym. J. 2000, $1,8$.

15. Lee, G.-Y.; Kim, J.-H.; Jang, H.-N.; Won, D.-S.; No, H. J.; Lee, J.-Y.; Rhee, B. K.; Choi, H.-D. Bull. Korean Chem. Soc. 2009, 30,661 .

16. Cisneros, J. I. Appl. Opt. 1998, 37, 5262.

17. Herman, W. N.; Hayden, L. M. J. Opt. Soc. Am. B. 1995, 12, 416.

18. Lee, G.-Y.; Kim, J.-H.; No, H. J.; Lee, J.-Y.; Rhee, B. K.; Choi, H.-D. J. Polym. Sci. Part A: Polym. Chem. 2009, 47, 1911. 